\title{
SPATIAL REPRESENTATION OF SURFACE WATER MONITORING AND ITS ASSESSMENT USING GEOSTATISTICAL AND NON-GEOSTATISTICAL TECHNIQUES IN GIS
}

\author{
Edon MALIQI ${ }^{1} 12^{*}$, Petar PENEV (i)2 \\ ${ }^{1} U B T$ - Higher Education Institution, Faculty of Architecture and Spatial Planning, Pristina, Kosova \\ ${ }^{2}$ University of Architecture, Civil Engineering and Geodesy, Sofia, Bulgaria
}

Received 11 February 2019; accepted 18 September 2019

\begin{abstract}
Continuous monitoring of surface water is essential in terms of heavy metals investigation. Therefore, surface water quality is an environmental aspect which should be analyzed and monitored depending on its spatial distribution. The aim of this study is to provide an overview for evaluation of surface water pollution in the Mitrovica area by applying spatial distribution using Geographic Information System (GIS), geostatistical and non-geostatistical techniques. Nowadays, GIS with the geostatistics and non-geostatistics are very frequently used techniques in environmental monitoring studies. By providing the spatial distribution, there is possibility to place the pollution values in space. The surface water pollution caused by heavy metals ( $\mathrm{As}, \mathrm{Cr}, \mathrm{Cu}, \mathrm{Ni}, \mathrm{Pb}, \mathrm{Zn}$ and $\mathrm{Cd}$ ) were sampled and analyzed from six monitoring stations in Sitnica river on different time series within three months countineously. The monitoring stations (samples) in Sitnica river were been distributed randomly. Pollution maps were produced using geostatistical and non-geostatistical (Spline and Kriging) approach. There were produced different pollution values in Sitnica river during the period of monitoring. Mainly the north part of Sitnica river has been poluted mostly with Heavy Metal Pollution Index (HPI) from 50 to 85 in the month of May, from 125 to 265 in the month of June and from 320 to 535 in the month of July. As well as the Metal Index (MI) from 0.60 to 2.05 in the month of May, June and July. The different statistical models were tested for geostatistical and non-geostatistical techniques in order to identify the best fitted technique for the pollution indices and the best interpolation techniques were selected on the basis of Mean Square Error (MSE), Mean Absolute Deviation (MAD), Root Mean Square Error (RMSE) and Mean Absolute Error (MAE) and Mean Absolute Percentage Error (MAPE). These statistical tested model have shown that the best fitted interpolation technique is Kriging because of the lowest values of MSE, MAD, RMSE, MAE and MAPE. In the study were involved statistical models such as correlation and regression, for showing the relation between time series datasets and interpolated pollution indices as well. The cartographic output derived from the study were raster maps ( $15 \mathrm{~m}$ spatial resolution) which represent the spatial distribution of surface water pollution as a result of monitoring process on time series. It is our believe that the present study will be used as a reference study for further environmental investigation and monitoring in Mitrovica since.
\end{abstract}

Keywords: surface water monitoring, spatial interpolation, GIS, cartographic output.

\section{Introduction}

Water is a compound with specific chemical properties which can dissolve diverse compounds or keep them suspended (World Health Organization [WHO], 2007). Today a serious environmental concern is currently the heavy metal contamination of surface water. In case of uncontrolled heavy metals in the environment, they can lead to anti-health effects such as poor growth and development, cancer, nervous system damage, and death (Fallahzadeh, Ghaneian, Miri, \& Dashti, 2017). Almost all mining activities impact the natural regional water systems and their effects may become obvious only after mining (Jahanshani \& Zare, 2015). The contamination of rivers with different pollutants presents a complex environmental problem. The industrial processes applied in "Trepca" Mining complex in Kosovo have resulted in enormous environmental pollution with heavy metals (Ferati \& Ylli, 2016). According to many studies in the previous years, the quality of rivers in Kosovo is a very big problem because of water pollution with heavy metals which is one of the biggest environmental problems.

In order to interpret correctly the surface water pollution, a useful tool seems to be GIS in conjuction with

*Corresponding author. E-mail: edon.maliqi@ubt-uni.net 
(non) geostatistical techniques. It allows to compile the maps of pollution distribution for whole study area, Sitnica river. Geostatistics is widely used to determine changes and spatial distribution of pollutants (Liu, Jang, \& Liao, 2004). As being an essential tool for estimating spatial continuous data, interpolation methods have been applied to various disciplines concerned with the Earth's surface (Tan \& Xu, 2014). Interpolation of data between sampled points is both powerful and timesaving (Simpson \& Wu, 2014).

Many researchers applied (non) geostatistical approach for analysis of spatial variations of surface water characteristics and monitoring. The measurement of pollutant concentration at all location is not always possible from time and cost perspectives in data collection stage (Kumar \& Ahmed, 2003). Therefore, prediction of other values in space based upon selectively measured values represents a reliable alternative. Thus, the geostatistical techniques can be used to predict the concentration of pollutants at unmeasured locations. Spatial interpolation (geostatistic) is the estimation of an unknown attribute values at unmeasured/unsampled points from measurements made at surrounding sites (known values of sampled points) (Tan \& Xu, 2014).

The basic idea in using geostatistics is that the characteristics of earth have some spatial continuity up to a certain lag distance (Gharabia et al., 2016). The geostatistical

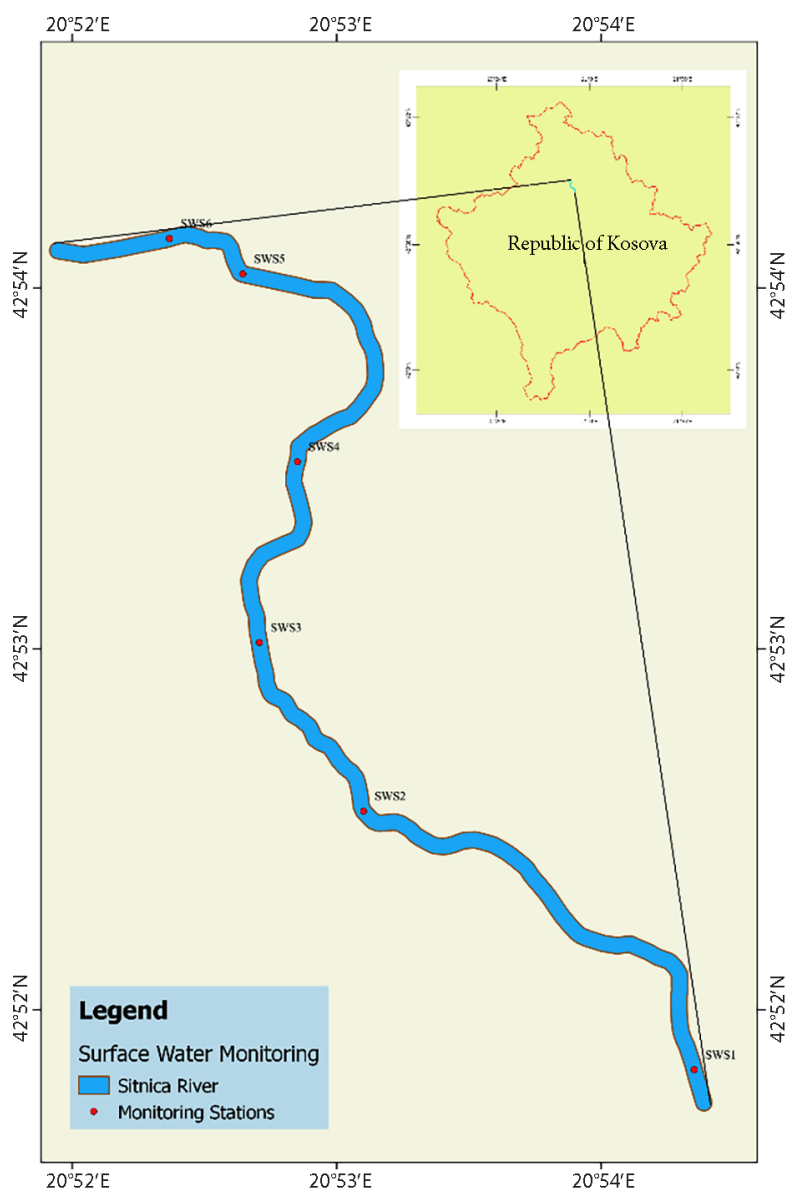

Figure 1. Study area map concepts and its applications are reported by different researchers around the world (Gharabia et al., 2016).

Spline and Kriging (Ordinary Kriging) interpolation techniques are mostly used for mapping spatial variability. In the present study these techniques will be used to interpolate the whole surface of the area based in the known points (samples/monitoring stations).

Many researches evaluate the surface water pollution on calculating the pollution indices such as the Heavy Metal Pollution Index (HPI) and Metal Index (MI), which are used to appreciate the pollution of surface water from industrial pollutants. The pollution indices (HPI and MI) have been calculated after water samples from monitoring stations were analysed in the certified laboratory. The critical HPI value is 100 , thus for better water quality the HPI value in a water sample should be less than 100. Likewise, the value of 1 for MI is a threshold of warning and for better water quality it should be less than 1. Generally, HPI, MI, Geographic Information System and (non) geostatistical techniques are used to monitor and map the spatial distribution of surface water pollution.

There detail objectives in this study are to; determine the level of concentration based in indices such as MI and HPI, in Sitnica river, develop an appropriate GIS system which will include spatial and non-spatial data of surface water monitoring, apply (non) geostatistical techniques in order to visualize surface water monitoring, analyse relationship between geostatistical and non-geostatistical techniques and relationship between time series monitoring, produce time series surface water monitoring maps.

The produced maps in this study in combination with knowledge of environmental pollution will be used for surface water monitoring. The present research provided realiable monitoring and assessment results for the surface water (Sitnica river) in Mitrovica, Kosovo.

\section{Study area}

The Mitrovica is bounded in the north part of Republic of Kosova, only $25 \mathrm{~km}$ from the capital Pristina (Maliqi \& Penev, 2018). The study area extends along to shore of the Sitnica river. It is located between the Latitude $42^{\circ} 57^{\prime} 02^{\prime \prime}$ and Longitude $20^{\circ} 54^{\prime} 36^{\prime \prime}$ in the North and Latitude $42^{\circ} 52^{\prime} 13^{\prime \prime}$ and Longitude $20^{\circ} 54^{\prime} 19^{\prime \prime}$ in the South. The minimum elevation is $502 \mathrm{~m}$ and the maximum elevation is $942 \mathrm{~m}$. The annual average precipitation is around $750 \mathrm{~mm}$ and moderate winds blowing predominantly from the northeast, average speed ranges $20 \mathrm{~m} / \mathrm{sec}$ to $4.4 \mathrm{~m} / \mathrm{sec}$. Average speed ranges $20 \mathrm{~m} / \mathrm{sec}$ to $4.4 \mathrm{~m} / \mathrm{sec}$. As well as the winters are colder with medium temperatures above $-10{ }^{\circ} \mathrm{C}$, but sometimes down to $-26{ }^{\circ} \mathrm{C}$. The summers are very hot with average temperatures of $20^{\circ} \mathrm{C}$, sometimes up to $37^{\circ} \mathrm{C}$.

Mitrovica city has a long history of lead and zinc metallurgy productions where unfortunately these mining operations have resulted in negative environmental impacts (Dekonta, 2009). It was one of the most important industrial areas of Kosova as well as one of the most important 
mining districts of Europe (Ferati \& Ylli, 2016). Within this study area lies a river named Sitnica, which has been investigated and monitored by set up 6 monitoring stations which were put randomly. In these monitoring stations were gathered water samples for a three months contineously, a water sample has been taken by a monitoring station every month. The monitoring stations were located within Sitnica river and the length of river which was monitored is approximately $8.2 \mathrm{~km}$. These monitoring stations have been enough in order to cover the whole distribution system of Sitnicia river within the study area. The mining tailings (Industrial Zone and Kelmend) are very close to Sitnica river and their affect in the river is considerable. Therefore, it worth to monitor the Sitnica river in order to investigate the presence of heavy metal in its water, as well as to visualize the contamination level as a final cartographic output of the study. In the next Figure $1 \mathrm{x}$ will be appeared the map of the study area.

\section{Data and methodology}

\subsection{Monitoring indices}

In order to monitor the extent of heavy metal pollution of surface water, two pollution indices were considered. These indices include the "Heavy Metal Pollution Index" (HPI) and "Metal Index" (MI). The HPI and MI were calculated using the ratios of monitored values in Sitnica river based on WHO (2011) permissible values. According to performed laboratory results, have been calculated the pollution indices (HPI and MI) by applying in Excel the known formulas given by Mohan, Nithila, and Reddy (1996) and Tamasi and Cini (2004). It can be considered as a zero base for spatial modeling of the pollution (contamination degree) in Sitnica river into GIS environment with intention of compilation serial thematic maps and diagram maps as a final cartographic outputs.

\subsection{Data sources}

The present study were conducted by using primary and secondary data. The primary data were considered data which were captured directly from the environment e.g. surface water samples (monitoring stations), location of monitoring stations, etc. The secondary data were considered data which are not captured directly from the environment e.g. chemical samples analysis, monitoring indices, etc. Three field works were carried out during three monitoring months (May, June and July, 2018). Eighteen water samples were collected by six monitoring stations, during these months. The surface water samples were collected within Sitnica river, every a month. Within Sitnica river were put the six monitoring stations for samples collection. The location of these monitoring stations is given in the Table 1 . The surface water samples were taken in correlation and full accordance with the EN ISO/CEI 17025 norms. As well as the conservation of samples were done according to the procedure of conservation refer to
American Public Health Association [APHA] (2005). The determination of contamination degree with heavy metals was done in full accordance with the EPA-3015 method and their reading were made in accordance with EPA6010C method as well. There were determined the degree of concetration of the $\mathrm{As}, \mathrm{Cr}, \mathrm{Cu}, \mathrm{Ni}, \mathrm{Pb}, \mathrm{Zn}$ and $\mathrm{Cd}$ within surface water samples. The degree of concentration of the mentioned metals was monitored in Trepça Laboratory by applying the SAA-F technique.

The Sitnica river as vector line in shapefile format were taken from Kosovo Cadastral Agency (KCA). To map the location of each surface water sample, GPS equipment (Leica) based on KOPOS (Kosovo Positioning System) was used to determine the position ( $\mathrm{Y}, \mathrm{X}$ coordinate and h (ellipsoidal height)) of surface water samples (Table 1).

Table 1. Location of monitoring stations (SWS - Surface Water Samples) based in field measurements (GPS)

\begin{tabular}{|c|c|c|c|}
\hline Station & Y & X & h \\
\hline SWS1 & 7492404.327 & 4746328.370 & 509 \\
\hline SWS2 & 7490361.838 & 4747922.644 & 504 \\
\hline SWS3 & 7489719.164 & 4748961.542 & 503 \\
\hline SWS4 & 7489956.560 & 4750073.624 & 505 \\
\hline SWS5 & 7489620.279 & 4751230.222 & 502 \\
\hline SWS6 & 7489166.972 & 4751448.604 & 499 \\
\hline
\end{tabular}

\subsection{Data processing}

Geographic information system (GIS) is widely used for collecting diverse spatial data and for overlay analysis in spatial register domain to represent spatially variable phenomena (Bonham-Carter, 1996; Babiker, Mohamed, Terao, Kato, \& Ohta, 2004; Gupta \& Srivastava, 2010). The water quality indices and GIS which synthesize different available water quality data into an easily understood format, provide a way to summarize overall water quality conditions in a manner that can be clearly communicated to policy makers (Singh, Raj, Tiwari, \& Mahato, 2013). The pollution maps or the contamination distribution maps in the Sitnica river were compiled using QGIS Desktop software, version 3.0.

During the data processing step, the first step was data harmonization and conversion process into appropriate formats to load the data in GIS environment. The source data were proccessed in QGIS software version 3.0 and the output, cartographic outputs, have been in the KosovaRef01 coordinate system (Kosovo coordinate system), whose parameters are know already. The numerous calculations of pollution indices (HPI and MI) in the surface water samples were done in Excel by applying known formulas as mentioned in the previous section. Spatial distribution of heavy metals pollution in Sitnica river were made by using geostatistical and non-geostatistical techniques (Spline and Kriging) in order to find out the spatial behavior of contamination degree in the Sitnica river. 
Numerous raster layers (15 m spatial resolution) were preparedin the present study using spatial interpolation techniques. The unsupervised classification methodology was used to classify and intepret raster maps. As well as the the relation and suitability between geostatistical and non-geostatistical techniques were made by applying the statistical appropriate models and different graphs were their output. The final output of the performed study will be an answer in the accuracy and suitability of two interpolation technqiues implemented as well. Therefore such analysis and calculations were made by using available statistical softwares. In the next chapters and sub-chapter will be demonstrated clearly the full study. The following figure (Figure 2), gives the workflow diagram and processing method used in the study.

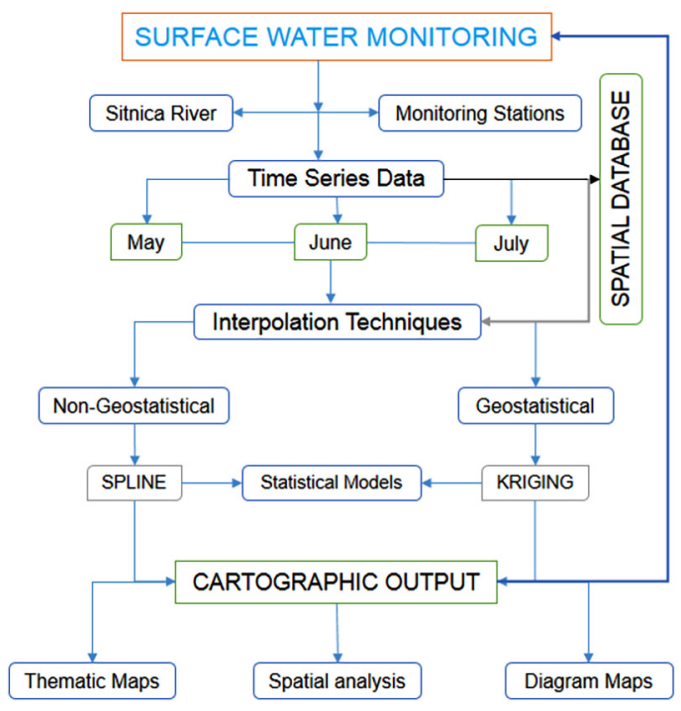

Figure 2. Workflow diagram

\section{Data modelling}

\subsection{Spatial database and Thematic Layers}

A database is any information collected and organized into groups (E. Maliqi, Hyseni, \& G. Maliqi, 2015). In the spatial database were included: datasets (vector and raster), feature classes, tabular and attribute data, topological rules and spatial reference system. The datasets include: surface water monitoring stations (points), cartographic outputs or raster maps (HPI and MI) based on geostatistical and non-geostatistical techniques for three time series (May, June and July, 2018). The spatial data type of feature classes were determined according to the data content and were stored in the spatial database. The feature classes have been used to create the graphical content of Sitnica river. The tabular and attribute data represent the feature attributes and data description. In the present study were included attributes and description data as follow: name of monitoring stations, position ( $\mathrm{Y}, \mathrm{X}$ and $\mathrm{h}$ ), name of river, heavy metals monitored, settlement, municipality, HPI and MI. This process will be repeated for three time series data. The topological rules were established between features in order to improve data concistency and facilitate data validation process. In this study the surface water samples have were taken within Sitnica river, thus the topoligical rule was points (monitoring stations) must be properly covered by the area (Sitnica river). The validation process of this criteria was fulfilled because it was verified automatically in GIS environment. Kosovaref01 reference system is used for the spatial database and thematic layers. A numerous thematic raster layers have been developed in the present study. The cartographic output (raster maps) were classified in different classes according to unsupervised classification methodology that represent the pollution level and water quality in Sitnica river. Each thematic layer will be used in terms of map use, data source, spatial relationship, map scale and symbology. The spatial database generated from analysis of surface water samples was integrated into GIS environment in order to produce the spatial distribution maps of pollution level in Sitnica river. The present study has demonstrated that spatial database and thematic layers were proposed and modelled in according with the above specifications thus it is an unique surface water monitoring study in general and a spatial database for surface water monitoring in particular. Three known models were developed during this study; conceptual, logical and physical model in order to facilate the database development.

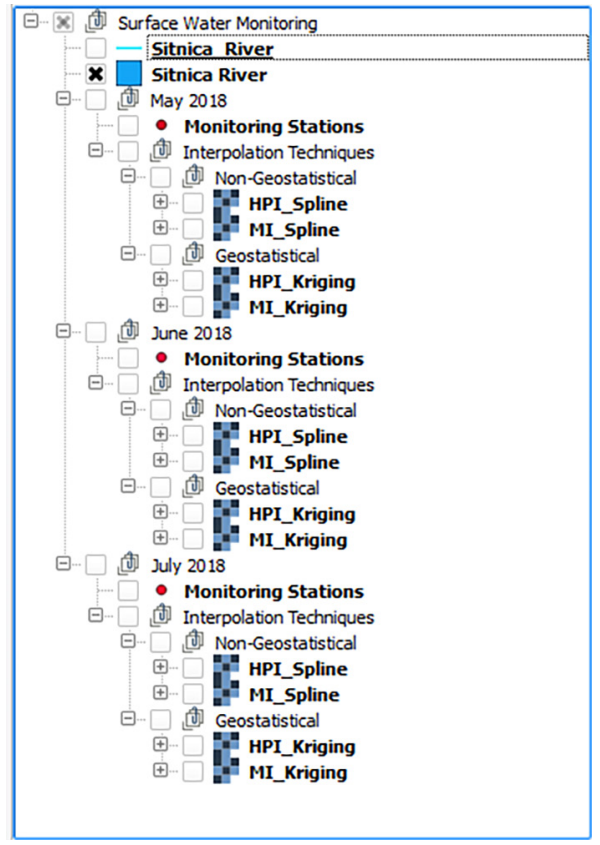

Figure 3. Data structure and thematic layers

\subsection{Spatial interpolation techniques}

The interpolation techniques help to assessment and monitor values for unknown point and create a continuous surface dataset of the spatial distribution. Spatial interpolation has continued to be an important tool for estimating continuous spatial environmental variables for 
effective decision making (Ikechukwu, Ebinne, Idorenyin, \& Raphael, 2017). Interpolation tools available in geographical information systems are useful and allow the operator to easily perform different kind of elaborations and to display them graphically in order to show the results in a way intelligible also to non-skilled subjects (Garnero \& Godone, 2013). Spatial interpolation techniques could be classified in two main groups: (1) mechanical or non-geostatistical technique in which included the Spline method and (2) geostatistical technique in which included Kriging method. In this study will be included the Spline technique and Kriging technique as well. Interpolation and value samplings have been carried out in QGIS software using these geostatistical and non-geostatistical technqiues. The present study compares the effectiveness of two interpolation technqiues, in which has been included geostatistical technique (Ordinary Kriging - OK) and non-geostatistical technique (Cubic Spline). By using QGIS software, these spatial interpolation techniques have been performed quickly and easily. The interpolation techniques have had very important role in the cartographic production such as surface water (Sitnica river) monitoring maps. Therefore, their usage have been undisputed. The attribute data samples including chemical analysis and pollution indices have been converted into spatial data (point data) for spatial interpolation to see the effective nature of changing water pollution level in the Sitnica river along the monitoring area. The appropriate resolution to produce raster pollution maps was chosen $15 \mathrm{~m}$ spatial resolution and it was selected during the interpolation process in GIS environment. The pollution in the surface water does not change rapidly within a small area therefore can be declared that $15 \mathrm{~m}$ spatial resolution has been one of the most appropriate spatial resolution.

The performance of spatial interpolation were analyzed according to Mean Squared Error (MSE), Mean Absolute Deviation (MAD), Root Mean Squar Error (RMSE), Mean Absolute Percentage Error (MAPE). The developed datasets in this study were chosen to determine interpolation performance and accuracy. The main purpose of this portion of the analysis is to determine which spatial interpolation techniques produces the lowest MSE, MAD, RMSE and MAPE. This methodology was used to rank the non-geostatistical (Spline) and geostatistical technique (Kriging). The performed statistical analysis have determined the best fit for of spatial interpolation techniques and the mentioned analysis have demonstrated that the lowest mentioned indices were to geostatistical spatial interpolation technique (Kriging) as is shown in the Table 2. Therefore, the analyzes have confirmed that Kriging is the best fit and accurate technique. The Table 2 shows the statistical analysis for time serie of May but in the same methodology were acted in three time series (May, June and July) and the results have confirmed the advantage of Kriging compared to Spline technique.
Table 2. The ranking of sptaial interpolation techniques

\begin{tabular}{|l|c|c|c|c|c|c|}
\hline \multicolumn{7}{|c|}{ Time series of May } \\
\hline \multirow{2}{*}{ Technique } & Indice & MSE & MAD & RMSE & MAPE & RANK \\
\hline \multirow{2}{*}{ Spline } & HPI & 202.8 & 11.3 & 14.24 & 26.04 & \multirow{2}{*}{2} \\
\cline { 2 - 6 } & MI & 0.09 & 0.22 & 0.29 & 47.86 & \\
\hline \multirow{2}{*}{ Kriging } & HPI & 302.5 & 14.8 & 17.39 & 34.40 & \multirow{2}{*}{1} \\
\cline { 2 - 6 } & MI & 0.04 & 0.17 & 0.20 & 31.86 & \\
\hline
\end{tabular}

\section{Cartographic output}

\subsection{Serial thematic maps and spatial analysis}

The cartographic output has been compilation of serial thematic maps that represent the monitoring indices in the Sitnica river as one of the objectives in the present study. Another objective of the study was performing the spatial analysis in GIS environment which will be detailed in this section. The serial thematic maps were produced in order to visualize the concetration of heavy metals in the Sitnica river, respectively the thematic maps represent pollution level (contamination degree) in the Sitnica river. The monitoring stations except that represent the monitoring parameters and monitoring indices (HPI and MI) in these monitoring points, help us to create (fill) the continous surface of pollution level in whole Sitnica river area. The inteprolation techniques help to assessment and monitor values for unknown point and create a continuous surface dataset of the spatial distribution. The compiled thematic maps, represents the surface water assessment in terms of heavy metals of 2018 years exactly May, June and July 2018 monitoring process. These serial thematic maps will be useful for reliable representation of pollution level in the Sitnica river and easily could be used for management scenarios in the Sitnica river from local and central institutions and enterprises. These serial thematic maps have been the first attempt to visualize pollution level in the Sitnica river and it is the first GIS implementation for surface water monitoring in Mitrovica (Kosovo) as well. Therefore, it is a suitable and sustainable study for further investigation and demonstration in the Sitnica river and surface water monitoring process in Kosovo in general.

The necessary elements of the thematic maps were calculated and visualization process has included mainly the Heavy Metal Pollution Index maps and Metal Index maps, in the raster format. Numerous thematic maps were compiled and produced during the study exactly 12 surface water monitoring maps have been cartographic output of the present study. These serial thematic maps include three time series data and those represent the serial monitoring maps in these time series, May, June and July 2018. The thematic maps have been output of two main interpolation techniques; Non-Geostatistical (Spline) and Geostatistical (Kriging) techniques. By performing the spatial analysis, there are useful detailed information for pollution level in every side of the sitnica river depending on the spatial resolution during the spatial interpolation. 
The performed spatial analaysis helped to determine the area with pollution level above permisseble values. And this was done in GIS environment by using spatial analysis tools.

The thematic maps of the May series data have contained four thematic maps with HPI and MI investigated indices and visualized by non-geostatistical technique (Cubic Spline) and Geostatistical technique (Ordinary Kriging - OK). The May series of monitoring process has showed that there are some differencies in the interpolated values. In the Spline spatial interpolation techniqe in HPI indice the lowest value has been under 30 and the highest value has been above 85 whereas to the Kriging spatial interpolation technique for the May series the lowest value has been under 20 and the highest value has been above 58. Thus, the Sitnica river fall in the high class (HPI > 30) based on the May series data. According to MI indice, the Spline interpolation technique has gave the minimum value of 0.392 and the maximum value of 1.02 . To Kriging interpolation technique has shown that the minimum value is 0.328 and the maximum value is 0.689 for the May series.

Two of spatial interpolation techniques have had the different pollution level values but the HPI of May series has shown the Sitnica river water fall under critical value of 100. And the MI has shown that based on this indicator to the Spline technique there is an area that is above critical value of 1 and this area fall in the "Slightly Affected" class $(1<\mathrm{MI}<2)$. Whereas it is not same in the Kriging spatial interpolation technique, to the Kriging it is under critical value of 1 respectively MI has shown that it falls in the "Pure" class $(0.3<\mathrm{MI}<1)$. The following maps (Figure 4) shows the situation detailed before.

By applying a simple query into GIS environment, the performed result has demonstrated that none of monitoring stations were above critical value of 100 for HPI. Therefore, the May series of data can be declared as series that represents no or low contamination situation in the Sitnica river. Because the performed result of query in GIS has been zero. The examined situation means that none of the monitoring stations have passed the critical value of 100. The MI indice has demonstrated that one of the monitoring stations (SWS5) has passed the critical value of 1 as well. Therefore, the monitoring process in month of May has confirmed that the contamination level does not present any concern as was presented in thematic maps except SWS5 monitoring station.

Based on June series data four thematic maps have been produced. The monitoring process of June with Spline spatial interpolation technique has shown that the minimum value of HPI was under 60 and the maximum value was until 265. According to Kriging interpolation technique the minimum value of HPI was from 30 to 80 and the maximum value of HPI was from 121 to 130 in the month of June. As well as the MI maps has shown that the minimum value was from 0.20 to 0.40 and the maximum value was until 1.20 whereas to the Kriging interpolation technique the minimum value has been from 0.20 to 0.55 and the maximum value has been from 0.71 to 0.80 .

In the same way as the May interpolation series, two of spatial interpolation techniques have had different pollution level values. To be more detailed the June thematic maps by using Spline interpolation technique show that the Sitnica water is strongly affected because most of the Sitnica area fall above critical value of 100 , as well as there is a part of Sitnica river in the "High" class (HPI > 30). According Kriging thematic maps the Sitnica water fall in the "High" class pollution (HPI > 30). Based on MI thematic maps by using Spline technique, there is a part that falls in the "Pure" class $(0.30<\mathrm{MI}<1)$ as well as the most of the sitnica water monitored fall in the "Slightly Affected" class $(1<\mathrm{MI}<2)$.

The GIS environment by performing the appropriate query, confirmed that four of the monitoring stations (SWS2, SWS3, SWS4, SWS5) have been above critical value of 100 for HPI. The query also demonstrated that SWS2 monitoring station has been above critical value of 1 for MI therefore this monitoring station has passed the threshold of warning. The visualization of thematic maps have proven these analytical analysis. Finally the monitoring process in the June series data has demonstrated that the situation in this series represented through thematic maps (Figure 5) show the concerns for water quality in the Sitnica river. As well as the polution level or the contamination degree in the Sitnica river should be addressed.

Four thematic maps for surface water monitoring indices in the month of July were compiled. The thematic maps according to Spline interpolation technique have shown that HPI maps have had the minimum value of HPI from 50 to 90 and the maximum value of HPI has been above 350. By using Kriging spatial interpolation technique HPI thematic maps have had the minimum value from 50 to 150 and the maximum value was above 325 . According MI map the minimum value based on Spline technique has been under 0.30 and the maximum value was until 2.00. As well as the MI map by Kriging has had the minimum value of from 0.30 to 0.85 and the maximum value was until 1.18. The generated thematic (Figure 5) maps that represpent the known pollution level in every part of the Sitnica river have showed that according to the Spline the Sitnica water fall above critical value of 100 and it is seriously affected (HPI > 100), the same situation has been to the Kriging spatial interpolation technique respectviely thematic maps produced by Kriging. The most of the Sitnica river falls above critical value of 100 ('Strongly Affected' class). Based on MI indicator, the Spline thematic map has shown that the most of the Sitnica area fall in the 'Moderately Affected' $(2<\mathrm{MI}<4)$. Whereas the Kriging thematic maps of MI has shown that the Sitnica water falls in the 'Slightly Affected' class $(1<\mathrm{MI}<2)$.

The July analysis data have shown the great concern about the performed results by applying a simple query if the monitoring stations have passed the critical value of 100 for HPI or not? And the genereted results 
demonstrated that all of monitoring stations (SWS1, SWS2, SWS3, SWS4, SWS5, SWS6) have been above critical value of 100 and many more of 100 . As well as the analysis about MI indice demonstrated that four of monitoring stations (SWS3, SWS4, SWS5, SWS6) were found above critical value of 1 . Thus, the July series of data respectively the thematic maps of this series represented the high contamination degree in the Sitnica river. Compared to the earliest series of data (May and June) in these monitoring stations, the July series has showed a big increase
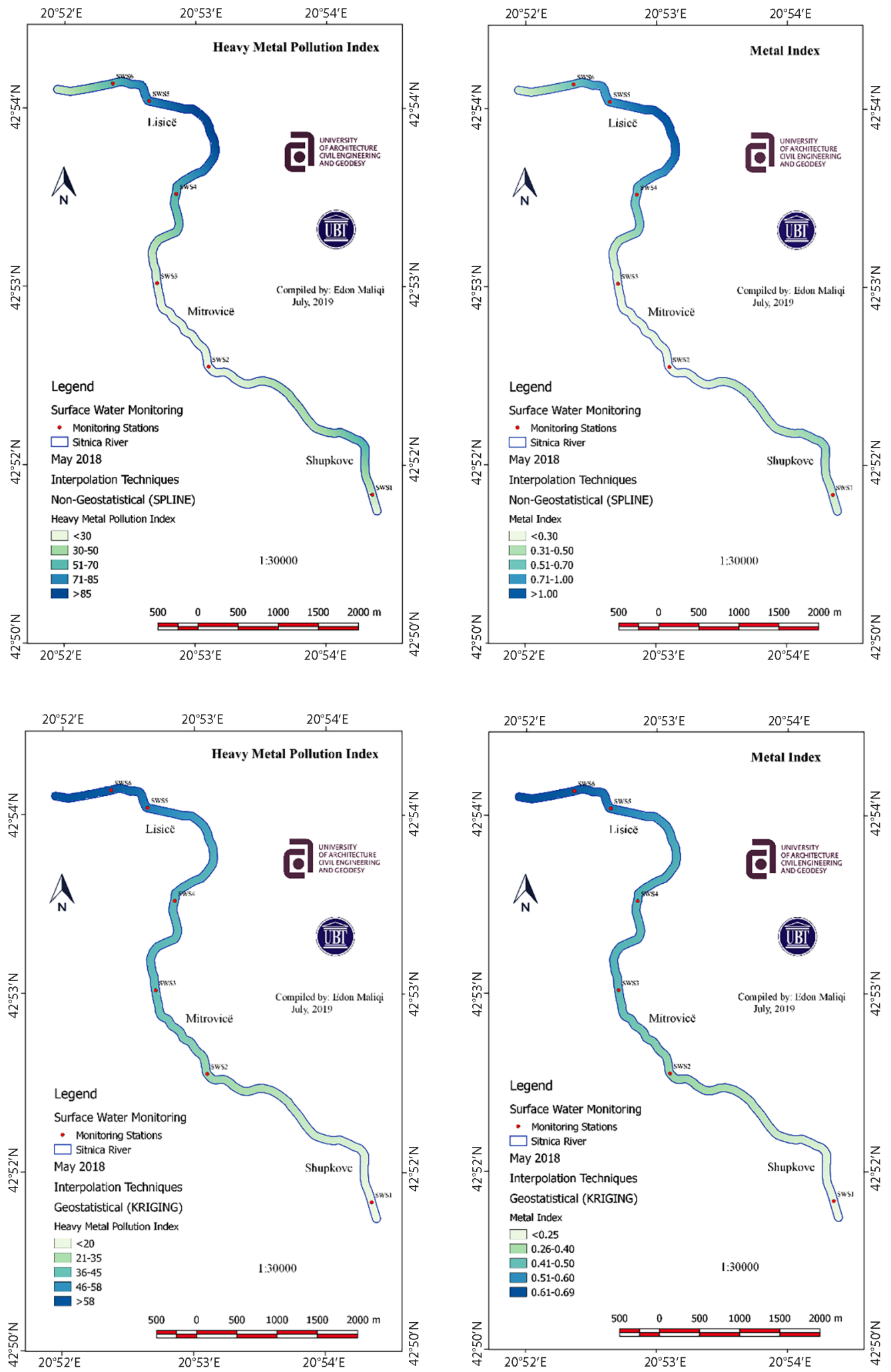

Figure 4. Thematic maps of May (2018) by using Spline and Kriging (HPI \& MI) 
of water pollution in this river. The results were based on laboratory examinations but logicaly it could be because of low volume of water in the summer season. So, the polutants have been the most present as ever. In general, the trend of contamination degree was grown progressively. The serial thematic maps (Figure 6) have demonstrated that the quality of water in the Sitnica river has decreased during three monitoring months (May, June and July).
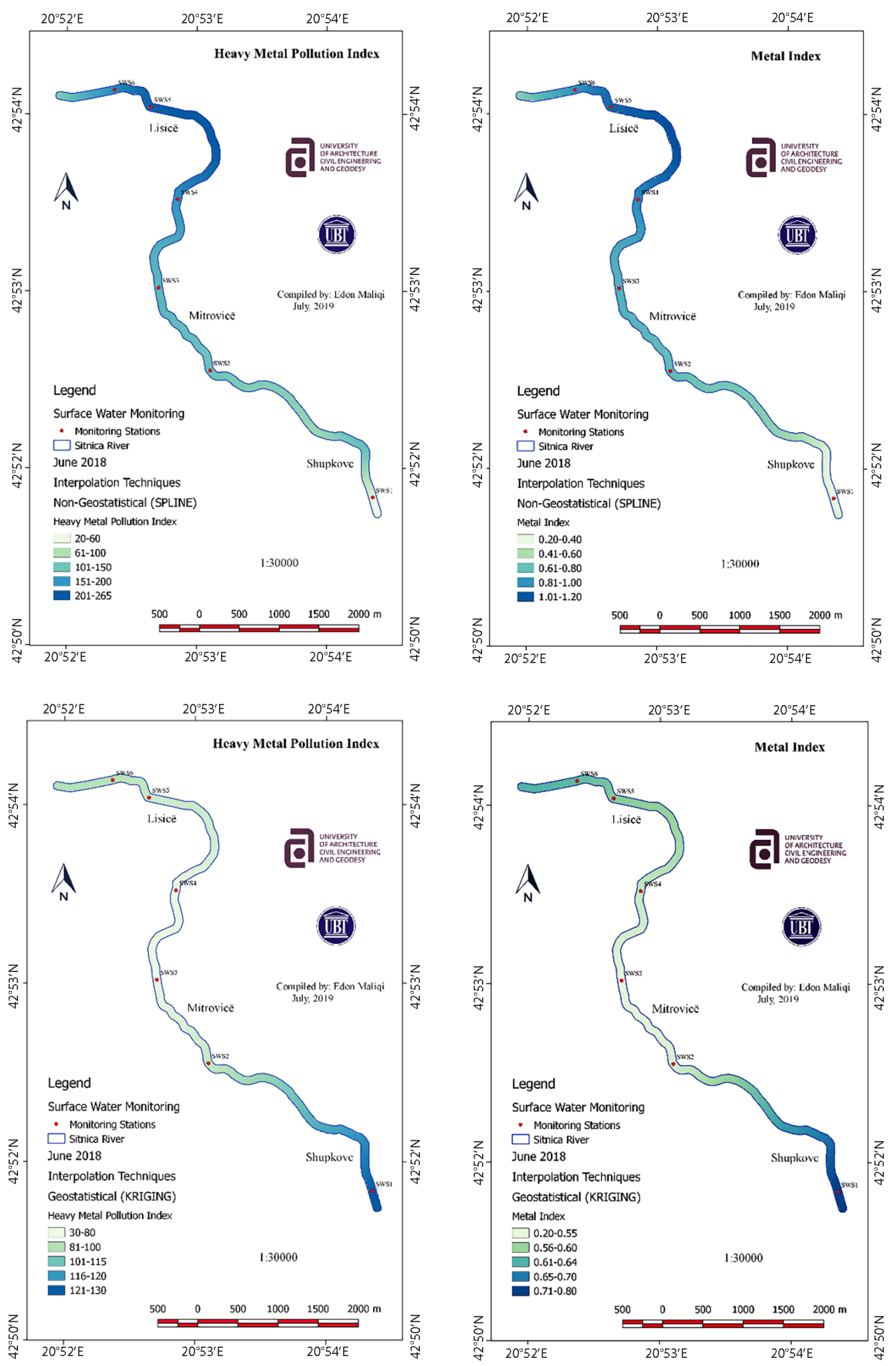

Figure 5. Thematic maps of June (2018) by using Spline and Kriging (HPI \& MI) 


\subsection{Diagram maps}

One of the first geographic animation using the method of cartodiagram (diagram map) was made by Caseti and Semple (1969). In the early years, a numerous authors have developed the appropriate methodology of cartodiagrams. The classification of cartodiagrams types depends by the informations such as the type of entities (point, line, polygon), level of measurement (nominal, ordinary, quantitative) and type of values (continuous
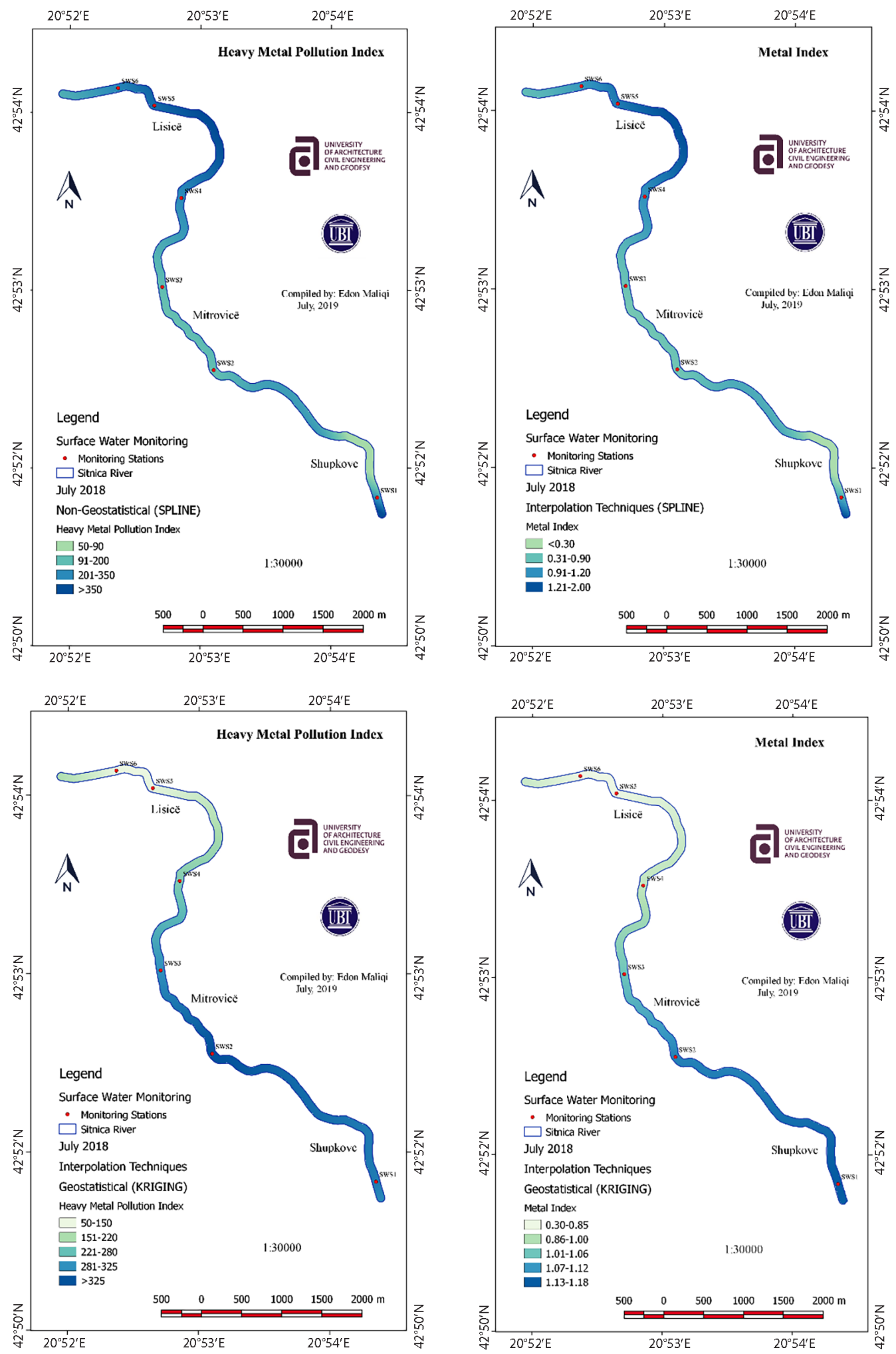

Figure 6. Thematic maps of July (2018) by using Spline and Kriging (HPI \& MI) 
or range). Should take into consideration the information of different types of cartodiagrams use 3D location. The cartodiagrams include some subtypes, one of them is histogram as well. The histogram method was selected in this paper to represent/quantify the pollution level in the Sitnica river. According to the above classification of the types of cartograms which have been used in the study were histograms type as point - quantitative - range. The thematic maps represented with histogram method have included time series data (May, June and July) and time series monitoring indices (HPI and MI). The histogram represents pollution level in monitoring stations based on HPI indice on three time series data (Figure 6). In the same way was acted for MI indice (Figure 6). The histogram analysis have demonstrated a difference in each time series data and monitoring stations as well. The histogram graph clearly has shown the pollution level in monitoring stations for May, June and July as a short-term monitoring process. By compilation of thematic maps in the present study were visualized the pollution levels with the cartodiagram as a useful technique to compare time series data in the Sitnica river. As mentioned in the previous section of the present study during analytical analysis performed in GIS environment by applying spatial query, the cartodiagram visualization technique of thematic maps help us to compare pollution levels and pollution indices in visual way and easily. Therefore, in the Sitnica river clearly can be compared the difference during time series data monitoring and monitoring indices as well. The following histogram maps (Figure 7) has proven details of the analytical analysis performed in GIS environment.

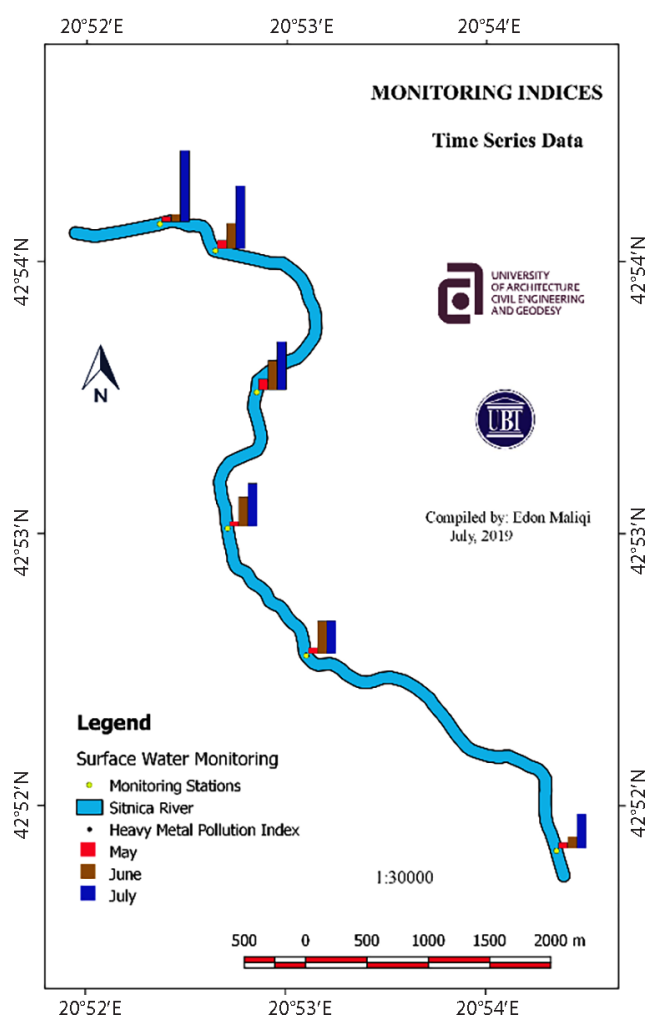

\subsection{Statistical analysis}

Multivariate statistical analyses including correlation and regression analyses were performed to estimate relationship between indices according to interpolation techniques. The Pearson correlation analyses were performed to examine relationship between Metal Index (MI) and Heavy Metal Pollution Index (HPI) in sense of spatial interpolation values. Statistical analyses were performed with Statistical Package for the Social Sciences (SPSS), except some analysis that was performed in Microsoft Excel 2016.

According to the Pearson correlation coefficient there is a relationship between MI and HPI in the Spline technique. Let's discuss serie by serie: May, June and July. In the month of May, the Pearson correlation coefficient to the Spline is $r=0.66$. This is a useful indicator to estimate the influence of MI in HPI. Then the importance of the Pearson correlation coefficient is determined based on the regression analyses and the regression analyses has confirmed that the correlation coefficient is important in the statistical link between indices. The Signifance F and $\mathrm{P}$ value to regression analyses were $1.5 \%$. In order to have important statistical link the regression coefficient should be from $1 \%$ to $5 \%$. In contrast to the Spline technique, to the Kriging is very strong correlation between MI and HPI with $r=0.98$ but the regression analyses have demonstrated that this relationship is not important statistically i.e. does not exist the important statistical link because of the regression coefficient (Significance $\mathrm{F}$ and $\mathrm{P}$ value) have been very under $1 \%$. To the June, the Perason correlation

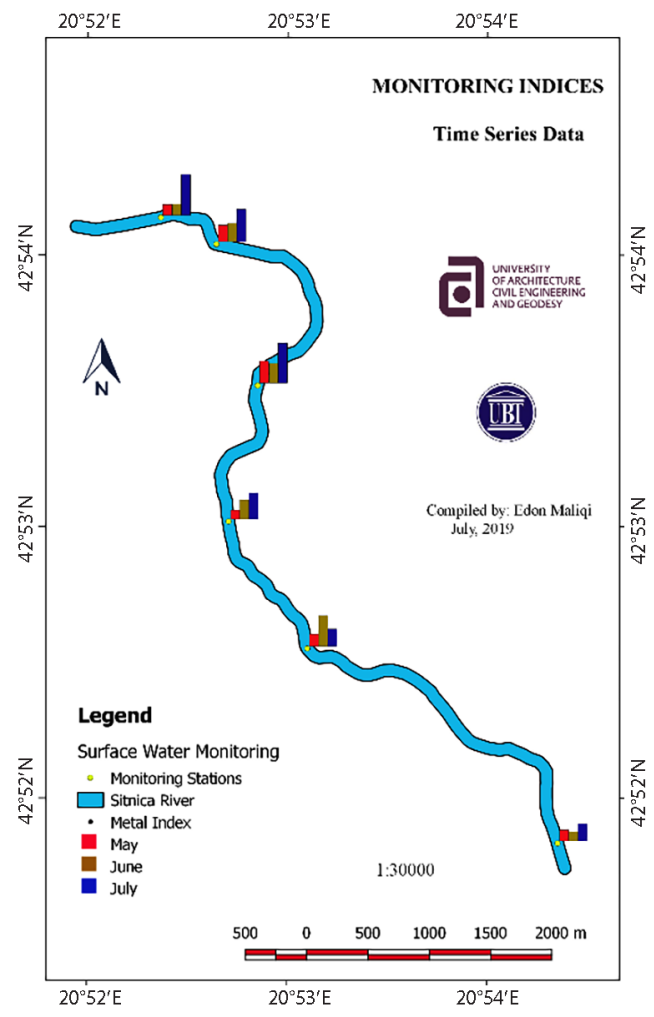

Figure 7. The histogram maps for level and distribution (HPI and MI, 2018) 
coefficient in the spline was $r=0.90$ and the Significance F and $\mathrm{P}$ value based on the regression analyses have proven the importance of statistical link between MI and HPI in the June serie. The F or P value have been $1.2 \%$. In the same serie (June) to the Kriging technique, the Pearson correlation coefficient was $r=0.70$ and the regression analyses have confirmed the important statistical link between Mi and HPI with F or P $1.14 \%$. As well as in the month of July, the Pearson correlation coefficient was $\mathrm{r}=$ 0.33 (low relationship) and the statistical importance of the relationship is not important statistically i.e. does not exist the statistical link between indices HPI and MI (F and $\mathrm{P}=5.2 \%)$. To the Kriging interpolation technique, the correlation coefficient was $\mathrm{r}=0.78$ and the $\mathrm{F}$ and $\mathrm{P}$ were $6.3 \%$ that means that there do not exist the important statistical relationship between indices in the sense of spatial interpolation. The next figures (Figure 8, Figure 9 and Figure 10) show the abovementioned details regarding correlation and regression analyses.

\section{Conclusions}

The study carried out the role of spatial interpolation techniques and GIS in monitoring surface water, the case of Sitnica river. The study has demonstrated that GIS in conjuction with (non) geostatistical techniques is a useful methodology for Sitnica river monitoring and assessment. Because of industry area close to Sitnica river the monitoring process of surface water river have had a great importance, its indices and parameters have been dynamic in different time series during a short-term monitoring process. The monitoring proccess based on three time series
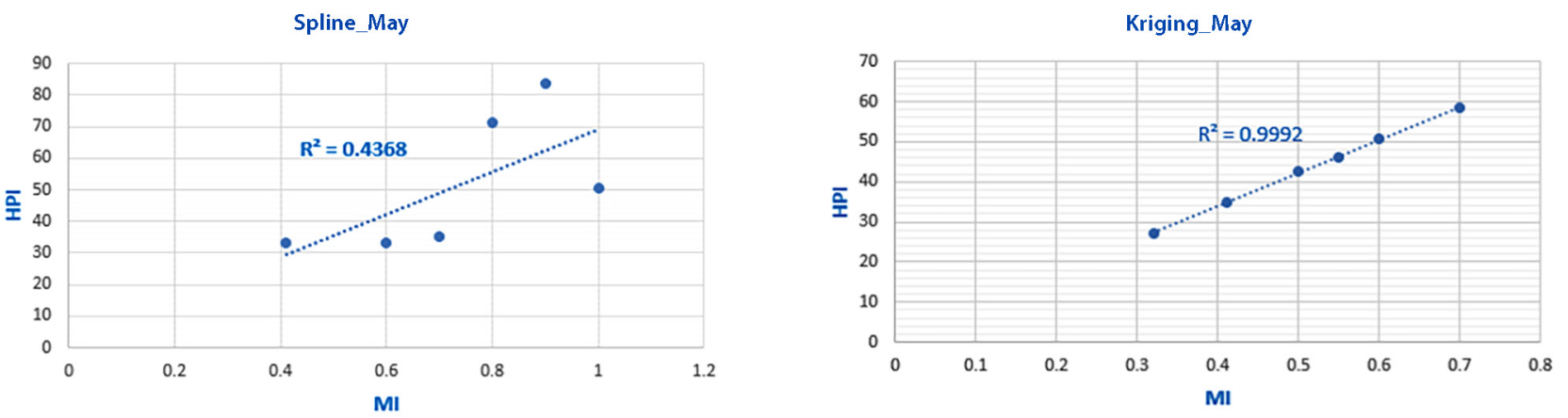

Figure 8. Correlation analysis of May, 2018 (Spline and Kriging)
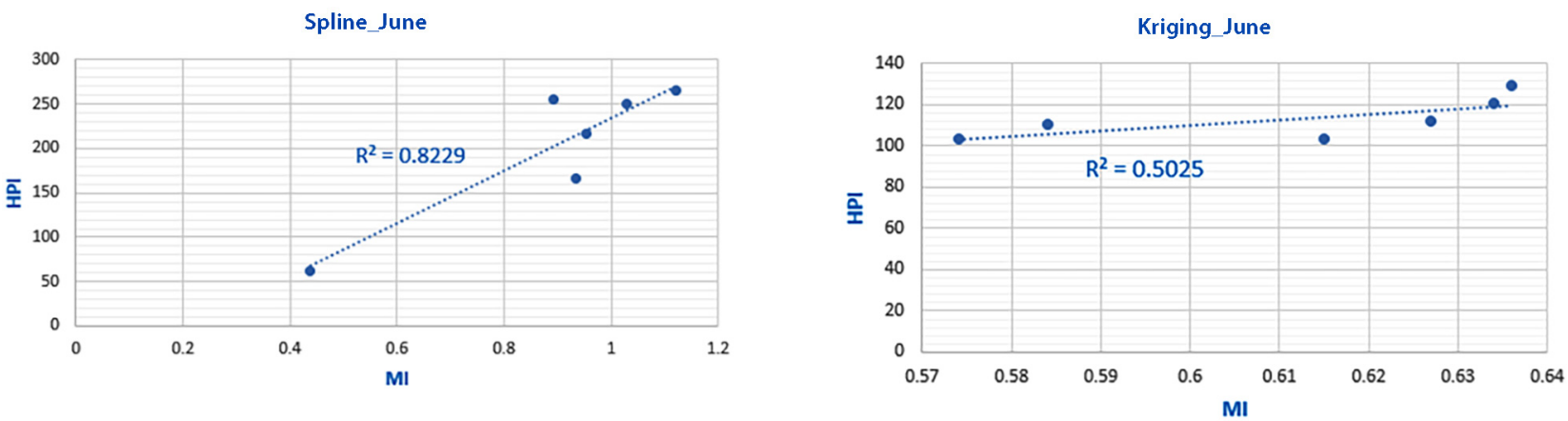

Figure 9. Correlation analysis of June, 2018 (Spline and Kriging)
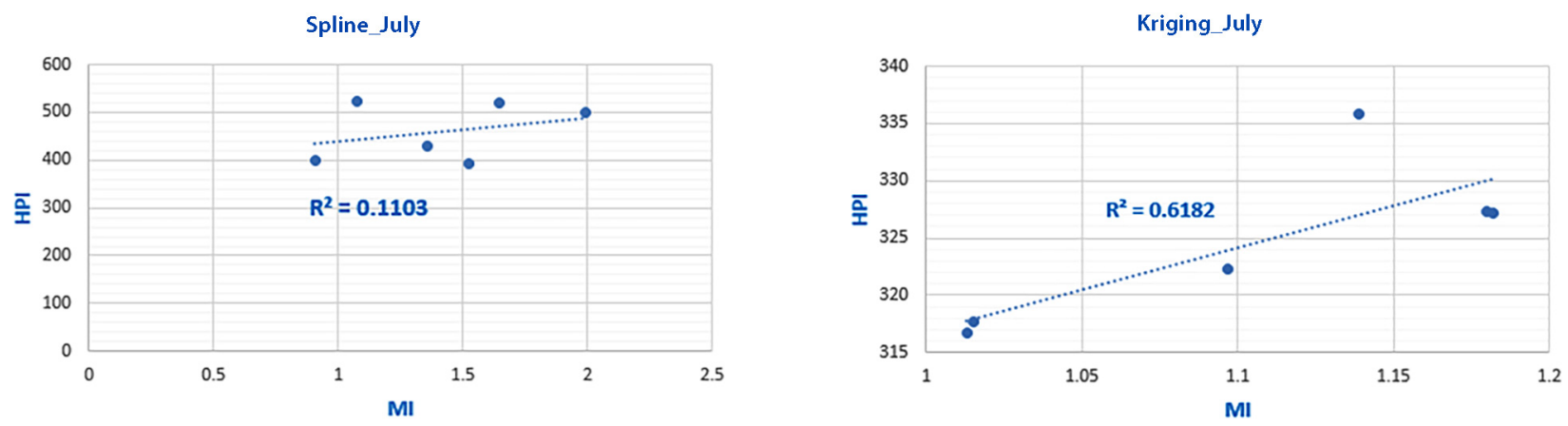

Figure 10. Correlation analysis of July, 2018 (Spline and Kriging) 
data (May, June and July) gave us a general overview of contamination level or water pollution in Sitnica river. The implementation of spatial interpolation techniques such as Spline and Kriging enabled the compilation of serial thematic maps in raster format. The spatial resolution of 15 $\mathrm{m}$ gave us a reliable and sustainable results which results could be used in the next studies as a base study for comparing time series data and studies in the Sitnica river. The spatial database and tabular data developed in this study can be converted easily in different computational formats in order to exchange data.

The statistical models in the study demonstrated that Kriging interpolation technique was the most fitted and accurate technique based on lowest values of MSE, MAD, RMSE, MAE and MAPE. Therefore, can be concluded that Kriging is advantageous compare to Spline according to the results from their performance. The time series thematic maps have shown the importance of visualitation of surface water pollution, in this sense the pollution of Sitnica river should be adressed based on computed data and serial thematic maps in this study. As well as the spatial analysis in GIS environment have confirmed the contamination degree which falls in many monitoring stations and areas above the permisseble value in time series. Furthermore, the performed statistical analysis clarified the relationship between time seried data and spatial interpolation techniques as well as there were analysed statistical links between interpolated values of indices through GIS. The main reason of Sitnica river pollution remains the industrial activity in this area and there is no action to manage mining tailings in that region. The discharge of stream networks into the Sitnica river remains another source of pollution as well. Therefore, following the approach given in the present paper, we can visualize the pollution level in Sitnica river every month for entire year. It worth to mention that the Sitnica water quality in terms of heavy metal pollution was above the permitable value of 100 according HPI indice and above the permitable value of 1 according MI indice. Especially, this situation has been recorded during the dry seasson.

In general, the present study has demonstrated that the followed methodology is an appropriate methodology in order to investigate the pollution level in Sitnica river.Thus this proccess should be continued from local and central institutions in Kosova, on a time basis.

\section{Aknowledgements}

The present study is part of Edon Maliqi's PhD thesis, which is supervised by Prof. Dr Petar Penev in the University of Architecture, Civil Engineering and Geodesy; Department of Photogrametry and Cartography; Sofia, Bulgaria.

\section{References}

American Public Health Association. (2005). Standard methods for the examination of water and wastewater (21st ed.). American Public Health Association, Washington DC.

Babiker, I., Mohamed, M., Terao, H., Kato, K., \& Ohta, K. (2004). Assessment of groundwater contamination by nitrate leaching from intensive vegetable cultivation using geographical information system. Environment International, 29(8), 10091017. https://doi.org/10.1016/S0160-4120(03)00095-3

Bonham-Carter, G. (1996). Geographic information systems for geoscientists: modeling with GIS. Computational Methods Geoscience, 13, 1-50.

Casseti, E \& Semple, R. (1969). Concerning the testing of spatial diffusion hypotheses. Geographical Analysis, 1(3), 254-259. https://doi.org/10.1111/j.1538-4632.1969.tb00622.x

Dekonta. (2009). Consulting services for Environmental Assessment and Remedial Action Plan for Mitrovica Industrial Park, Kosovo. UNDP.

Fallahzadeh, R., Ghaneian, M., Miri, M. \& Dashti, M. (2017). Spatial analysis and health risk assessment of heavy metals concentration in drinking water resources. Environmental Science and Pollution Research, 24, 24790-24802. https://doi.org/10.1007/s11356-017-0102-3

Ferati, F., \& Ylli, K. A. (2016). Multivariate statistical analysis for the surface water quality of Trepça and Sitnica Rivers, Kosovo. Journal of International Environmental Application and Science, 11(1), 92-99.

Garnero, G., \& Godone, D. (2013). Comparisons between different interpolation techniques. In The International Archives of the Photogrammetry, Remote Sensing and Spatial Information Sciences, Volume XL-5/W3. Padua, Italy. https://doi.org/10.5194/isprsarchives-XL-5-W3-139-2013

Gharabia, A., Gharabia, S., Abushkak, Th., Wafi, H., Aish, A., Zelenakova, M., \& Pilla, F. (2016). Groundwater quality evaluation using GIS based geostatistical algorithms. Journal of Geoscience and Environment Protection, 4, 89-103. https://doi.org/10.4236/gep.2016.42011

Gupta, M. \& Srivastava, P. (2010). Integrating GIS and remote sensing for identification of groundwater potential zones in the hilly terrain of Pavagarh, Gujarat, India. Water International, 35, 233-245. https://doi.org/10.1080/02508061003664419

Ikechukwu, M., Ebinne, E., Idorenyin, U., \& Raphael, N. (2017). Accuracy assessment and comparative analysis of IDW, spline and kriging in spatial interpolation of landform (topography): an experimental study. Journal of Geographic Information System, 9, 354-371. https://doi.org/10.4236/jgis.2017.93022

Jahanshani, R., \& Zare, M. (2015). Assemsent of heavy metal pollution in groundwater of Golgohar iron ore mine area, Iran. Envrioenmental Eart Science, 74, 505-520. https://doi.org/10.1007/s12665-015-4057-8

Kumar, D., \& Ahmed, S. (2003). Seasonal behaviour of spatial variability of groundwater level in a granitic aquifer in monsoon climate. Current Science, 84, 188-196.

Liu, C. W., Jang, C. S., \& Liao, C. M. (2004). Evaluation of arsenic contamination potential using indicator kriging in the YunLin aquifer (Taiwan). Science of the Total Environment, 321(13), 173-188. https://doi.org/10.1016/j.scitotenv.2003.09.002

Maliqi, E., \& Penev, P. (2018). Monitoring of vegetation change by using RS and GIS techniques in Mitrovica, Kosovo. Journal of Cartography and Geographic Information Systems, 1, 1-13. https://doi.org/10.23977/jcgis.2018.11001 
Maliqi, E., Hyseni, D., \& Maliqi, G. (2015). Application of GIS In the special zone of interest "Gumnishtë" - Kosovo. Micro, Macro \& Mezzo Geoinformation, (4), 49-59.

Mohan, S., Nithila, P., \& Reddy, S. (1996). Estimation of heavy metal in drinking water and development of heavy metal pollution index. Journal of Environmental Science and Health. Part A: Environmental Science and Engineering and Toxicology, 31(2), 283-289. https://doi.org/10.1080/10934529609376357

Simpson, G., \& Wu, Y. (2014). Accuracy and effort of interpolation and sampling: Can GIS help lower field costs? ISPRS International Journal of Geo-Information, 3, 1317-1333. https://doi.org/10.3390/ijgi3041317

Singh, A., Raj, B., Tiwari, A., \& Mahato, M. (2013). Evaluation of hydrogeochemical processes and groundwater quality in the Jhansi district of Bundelkhand region, India. Environmental Earth Science, 70(3), 1225-1247.

https://doi.org/10.1007/s12665-012-2209-7
Tamasi, G., \& Cini, R. (2004). Heavy metals in drinking waters from Mount Amiata (Tuscany, Italy). Possible risks from arsenic for public health in the province of Siena. Science of the Total Environment, 327(1-3), 41-51. https://doi.org/10.1016/j.scitotenv.2003.10.011

Tan, Q., \& Xu, X. (2014). Comparative analysis of spatial interpolation methods: an experimental study. Sensors \& Tranducers, 165(2), 155-163.

World Health Organization. (2007). Quality assurance of pharmaceuticals: a compendium of guidelines and related materials. Good manufacturing practices and inspection. World Health Organization, Geneva.

World Health Organization. (2017). Guidelines for drinking water quality: Vol. 1, recommendations (4 ed.). World Health Organization, Geneva. 